\title{
Production of IL-1 $\beta$ and Inflammasome with Up-Regulated Expressions of NOD-Like Receptor Related Genes in Toxoplasma gondii-Infected THP-1 Macrophages
}

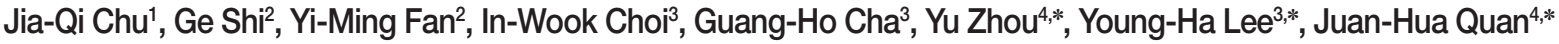 \\ 'Stem Cell Research and Cellular Therapy Center and Laboratory Institute of Minimally Invasive Orthopedic Surgery, Affiliated Hospital of Guangdong \\ Medical University, Zhanjiang, China; '² Department of Dermatology, Affiliated Hospital of Guangdong Medical University, Zhanjiang, China; \\ ${ }^{3}$ Department of Infection Biology, Chungnam National University School of Medicine, Daejeon 35015, Korea; ${ }^{4}$ Department of Gastroenterology, \\ Affiliated Hospital of Guangdong Medical University, Zhanijang, China
}

\begin{abstract}
Toxoplasma gondii is an obligate intracellular parasite that stimulates production of high levels of proinflammatory cytokines, which are important for innate immunity. NLRs, i.e., nucleotide-binding oligomerization domain (NOD)-like receptors, play a crucial role as innate immune sensors and form multiprotein complexes called inflammasomes, which mediate caspase-1-dependent processing of pro-IL-1 $\beta$. To elucidate the role of inflammasome components in T. gondiiinfected THP-1 macrophages, we examined inflammasome-related gene expression and mechanisms of inflammasomeregulated cytokine IL-1 $\beta$ secretion. The results revealed a significant upregulation of IL-1 $\beta$ after T. gondii infection. T. gondii infection also upregulated the expression of inflammasome sensors, including NLRP1, NLRP3, NLRC4, NLRP6, NLRP8, NLRP13, AIM2, and NAIP, in a time-dependent manner. The infection also upregulated inflammasome adaptor protein ASC and caspase-1 mRNA levels. From this study, we newly found that $T$. gondii infection regulates NLRC4, NLRP6, NLRP8, NLRP13, AIM2, and neuronal apoptosis inhibitor protein (NAIP) gene expressions in THP-1 macrophages and that the role of the inflammasome-related genes may be critical for mediating the innate immune responses to $T$. gondii infection.
\end{abstract}

Key words: Toxoplasma gondii, inflammasome, nucleotide-binding oligomerization domain (NOD)-like receptor (NLR), THP-1 macrophage, qRT-PCR

\section{INTRODUCTION}

Toxoplasma gondii is an obligate intracellular protozoan parasite that can invade and replicate in all nucleated cells in a wide range of host species. At least one-third of the world's population is reportedly infected with T. gondii [1]. Although infection in immunocompetent humans is usually asymptomatic, T. gondii can lead to a life-threatening disease in fetuses or newborns of primary-infected mothers and in immunocompromised patients after activation of dormant parasites [2].

The innate immune system plays an important role in sensing pathogens and triggering biological mechanisms to control infection and eliminate pathogens $[3,4]$. The presence of pathogens is detected by a limited number of germline-encod-

- Received 6 October 2016, revised 5 December 2016, accepted 5 December 2016. *Corresponding author (ahdg2005@126.com; yhalee@cnu.ac.kr; qih0880@163.com) (c) 2016, Korean Society for Parasitology and Tropical Medicine This is an Open Access article distributed under the terms of the Creative Commons Attribution Non-Commercial License (http://creativecommons.org/licenses/by-nc/4.0) which permits unrestricted non-commercial use, distribution, and reproduction in any medium, provided the original work is properly cited. ed pattern recognition receptors (PRRs) that have evolved to sense conserved microbial molecules. PRRs are expressed by cells, such as monocytes, macrophages, dendritic cells, neutrophils, and epithelial cells, as well as other cells of the adaptive immune system [5]. PRRs include Toll-like receptors (TLRs), C-type lectin receptors, RIG-like receptors, and nucleotidebinding oligomerization domain (NOD)-like receptors (NLRs) $[6,7]$. Significant effort has been dedicated to determining the specific TLRs responsible for the initial sensing of T. gondii, and multiple TLRs have been reported to participate in T. gondii sensing [8].

NLRs are a large group of cytosolic sensors whose main function is to modulate the expression of proinflammatory cytokines $[9,10]$. NLR proteins have a common domain organization with a central nucleotide-binding oligomerization domain (NOD or NACHT), a C-terminal leucine-rich repeat domain, and a variable $\mathrm{N}$-terminal protein-protein interaction domain $[9,10]$. Members of the NLR family assemble into large multiprotein complexes, termed inflammasomes, that can be activated by cellular pathogens (bacteria, fungi, viruses, 
and protozoa) or stress to engage innate immune defenses [1113]. Inflammasomes activate caspase-1, a proteolytic enzyme that cleaves and activates IL-1 $\beta$ and IL-18 [11,12]. The NLR family includes more than 23 members in humans and approximately 34 in mice. Some NLR members are reportedly involved in T. gondii infection of mice or cells [14-18]; however, the functions of many sensor proteins, including NLR4, NLRP6, NLRP8, NLRP10, NLRP12, NLRP13, NLRP14 and neuronal apoptosis inhibitor protein (NAIP), in T. gondii-infected cells remain unknown.

IL-1 $\beta$ is a critical cytokine that acts as a pyrogen to amplify the proinflammatory response during infection with various pathogens $[19,20]$. Due to its potent inflammatory activity, IL$1 \beta$ plays a critical role in host defenses and innate immunity against pathogens [21]. The current model for IL-1 $\beta$ regulation is that TLR activation and NF- $\mathrm{kB}$ signaling induce IL- $1 \beta$ transcription, and then the mRNA is subsequently translated into pro-IL-1 $\beta$. A second signal then activates the inflammasome for proteolytic processing of the zymogen into mature, bioactive IL-1 $\beta$, which can be released from cells [22]. T. gondii has been shown to induce IL-1 $\beta$ in multiple human cell types in vitro, including monocytes, foreskin fibroblasts, and retinal pigment epithelial cells $[17,18]$. Exogenous administration of IL-1 $\beta$ is protective against lethal $T$. gondii infection in vivo [23]. Although T. gondii infection results in IL-1 $\beta$ secretion, the precise mechanism of IL-1 $\beta$ production in macrophages has not yet been elucidated.

To understand inflammasome-related gene and protein expression and the mechanisms of inflammasome-regulated inflammatory cytokine secretion, we evaluated inflammasome sensors, including NLRP1, NLRP3, NLRC4 (nucleotide-binding domain leucine-rich repeats protein family), AIM2 (HIN 200 protein family), a subset of NLRs (NLRP6, NLRP8, NLRP13), NAIP, adaptor molecule ASC (apoptosis-associated speck-like protein containing a caspase recruitment domain), and caspase-1 gene expression in T. gondii-infected THP-1 macrophages.

\section{MATERIALS AND METHODS}

\section{T. gondii maintenance}

Tachyzoites of $T$. gondii RH strain were maintained as described previously, with some modifications [24]. Briefly, human retinal pigment epithelial cells, ARPE-19 (ATCC, Manassas, Virginia, USA), were cultured in a 1:1 mixture of Dulbec- co's modified Eagle's medium (DMEM) with F12 (DMEM/ F12) supplemented with 10\% heat-inactivated fetal bovine serum (FBS) and antibiotic-antimycotics (all from Gibco, Grand Island, New York, USA).

ARPE-19 cells were infected with RH strain of T. gondii using a multiplicity of infection (MOI) of 5 and incubated at $37^{\circ} \mathrm{C}$ and $5 \% \mathrm{CO}_{2}$ for 2-3 days. Following spontaneous host cell rupture, parasites and host cell debris were washed in cold PBS. The final pellet was resuspended in cold DMEM and then passed through a 26-gauge needle and a $5.0 \mu \mathrm{m}$ pore filter (Millipore, Billerica, Massachusetts, USA).

\section{In vitro culture of THP-1 monocytes and differentiation into macrophages}

A human leukocyte cell line, THP-1 (ATCC) was cultured in RPMI 1640 medium supplemented with 10\% FBS and antibiotic-antimycotics (Gibco). Cells were incubated at $37^{\circ} \mathrm{C}$ in a humidified atmosphere of $5 \% \mathrm{CO}_{2}$ and $95 \%$ air. To induce differentiation into macrophages, THP-1 cells were treated with 100 nM PMA (Sigma-Aldrich, St. Louis, Missouri, USA) for $24 \mathrm{hr}$. Non-adherent cells were removed by aspiration, and adherent macrophages were washed with RPMI 1640 medium 3 times before stabilizing for $48 \mathrm{hr}$ in cell culture medium [24].

\section{IL-1 $\beta$ ELISA}

Differentiated THP-1 cells were mock-infected or infected with RH strain of T. gondii at an MOI of 10 for $4 \mathrm{hr}$ and $8 \mathrm{hr}$. The supernatant from mock-infected or T. gondii-infected THP1 cells was collected in triplicate, and IL-1 $\beta$ levels were measured using commercially available IL-1 $1 \beta$ ELISA kits according to the manufacturer's instructions (eBioscience, San Diego, California, USA). The cytokine concentrations of the samples were calculated from standard curves obtained using recombinant cytokines. The results were expressed in picograms per milliliter.

\section{Western blotting}

The protein samples were separated by SDS-PAGE and transferred onto polyvinylidene difluoride membranes and probed with the relevant antibodies. The blots were developed using an enhanced ECL chemiluminescence detection kit (GE Healthcare, Little Chalfont, UK). The primary antibodies used were rabbit anti-IL1 $\beta$, ASC, NLRP3, and NLRC4 (Cell Signaling Technology, Danvers, Massachusetts, USA) and mouse 
Table 1. Primer sequences used for real-time quantitative reverse transcriptase PCR (qRT-PCR) in this study

\begin{tabular}{|c|c|c|c|}
\hline Gene name & GeneBank accession no. & Primer sequence $\left(5^{\prime}-3^{\prime}\right)$ & Product size (bp) \\
\hline$I L-1 \beta$ & NM_000576.2 & $\begin{array}{l}\text { F-CCACAGACCTTCCAGGAGAA } \\
\text { R-GTGATCGTACAGGTGCATCG }\end{array}$ & 121 \\
\hline NLRP1 & NM_014922.4 & $\begin{array}{l}\text { F-ATACGAAGCCTITGGGGACT } \\
\text { R-ACAAAGCAGAGACCCGTGTT }\end{array}$ & 148 \\
\hline NLRP3 & XM_011544055.2 & $\begin{array}{l}\text { F-AAAGGAAGTGGACTGCGAGA } \\
\text { R-TTCAAACGACTCCCTGGAAC }\end{array}$ & 129 \\
\hline NLRC4 & XM_017004619.1 & $\begin{array}{l}\text { F-GGAAAGTGCAAGGCTCTGAC } \\
\text { R-TGTCTGCTTCCTGATTGTGC }\end{array}$ & 129 \\
\hline AlM2 & XM_005245616.4 & $\begin{array}{l}\text { F-AGCCTGAACAGAAACAGATGG } \\
\text { R-CTTCTTGGGTCTCAAACGTGA }\end{array}$ & 120 \\
\hline ASC & NM_145182.2 & $\begin{array}{l}\text { F-CTGACGGATGAGCAGTACCA } \\
\text { R-CAAGTCCTTGCAGGTCCAGT }\end{array}$ & 108 \\
\hline CASP1 & XM_017018396.1 & $\begin{array}{l}\text { F-GGGGTACAGCGTAGATGTGAA } \\
\text { R-CTTCCCGAATACCATGAGACA }\end{array}$ & 137 \\
\hline NLRP6 & XM_017017253.1 & $\begin{array}{l}\text { F-CTGTTCTGAGCTACTGCGTGAG } \\
\text { R-AGGCTCTTCTTCTTCTTCTCCTG }\end{array}$ & 100 \\
\hline NLRP7 & XM_011526601.2 & $\begin{array}{l}\text { F-TAACCCGTAGCACCTGTCATC } \\
\text { R-GGTCTTCTTCCCAATGAAAGC }\end{array}$ & 101 \\
\hline NLRP8 & NM_001317000.1 & $\begin{array}{l}\text { F-CGCTGGTGTGCTTCTACTTC } \\
\text { R-GGTCGGGTITGGACATAATCT }\end{array}$ & 130 \\
\hline NLRP9 & XM_011526894.2 & $\begin{array}{l}\text { F-CTAGCCTCTCCCAGTCTGACAT } \\
\text { R-GCGATGTCTTCACAAACTTCAC }\end{array}$ & 121 \\
\hline NLRP10 & XM_011520043.2 & $\begin{array}{l}\text { F-GTCACGGTGGAGGCTCTATIT } \\
\text { R-CGAGAGTTGTCTITCCAGTGC }\end{array}$ & 100 \\
\hline NLRP11 & NM_001297743.1 & $\begin{array}{l}\text { F-TAGATTGCTGCACGACCTTG } \\
\text { R-GGCACAGACCCACGAGTATT }\end{array}$ & 135 \\
\hline NLRP12 & XM_017027467.1 & $\begin{array}{l}\text { F-CGACCTITACCTGACCAACAA } \\
\text { R-AGGTCCATCCCAAATAACCAG }\end{array}$ & 114 \\
\hline NLRP13 & NM_001321057.1 & $\begin{array}{l}\text { F-ATGGTGTGTTGGACCGTATGT } \\
\text { R-GCCAAATCTACCTCTGCTGT }\end{array}$ & 140 \\
\hline NLRP14 & XM_011520044.1 & $\begin{array}{l}\text { F-CCGCTTGTACTTGTCTGAAGC } \\
\text { R-GCCTCCATCTACTGGTGTGAA }\end{array}$ & 122 \\
\hline NAIP & XM_011543413.2 & $\begin{array}{l}\text { F-AGTACTIITCGACCACCCAGA } \\
\text { R-TAGTTGGCACCTGTGATTTGTC }\end{array}$ & 135 \\
\hline HPRT1 & NM_000194.2 & $\begin{array}{l}\text { F-GACCAGTCAACAGGGGACAT } \\
\text { R-CTGCATTGTITGCCAGTGT }\end{array}$ & 111 \\
\hline
\end{tabular}

anti-a-tubulin (Santa Cruz Biotechnology, Santa Cruz, California, USA).

\section{RNA extraction and quantitative real-time PCR (qRT- PCR)}

Differentiated THP-1 cells were mock-infected or infected with RH strain of T. gondii at an MOI of 10 for $4 \mathrm{hr}$ and $8 \mathrm{hr}$. Total cellular RNA was extracted using TRIzol Reagent (Invitrogen Life Technologies, Carlsbad, California, USA). RNA ( $2 \mu \mathrm{g})$ was reverse transcribed in a final volume of $20 \mu \mathrm{l}$ using Superscript II reverse transcriptase (Invitrogen Life Technologies), as specified by the manufacturer, and then subjected to PCR using specific primer sets (Table 1). qRT-PCR was conducted using an ABI 7500 FAST System (Applied Biosystems, Carlsbad, California, USA). cDNA (100 ng) was subjected to qRT-PCR in a $20 \mu \mathrm{l}$ reaction volume using SYBR-Premix Ex Taq II (Takara Bio Inc., Otsu, Japan). The hypoxanthine phosphoribosyltransferase 1 (HPRT1) gene was amplified for normalization of the cDNA amount used in qRT-PCR. Reactions were carried out in triplicate, and the data were analyzed using the $2^{-\Delta \Delta \mathrm{Ct}}$ method.

\section{Statistical analysis}

Results were expressed as means \pm SD from at least 3 independent experiments unless otherwise indicated. The statistical significance of the data was determined by unpaired Student's $t$-test or 1-way ANOVA. $P$-values of $<0.05$ were considered significant. 


\section{RESULTS}

\section{Up-regulation of IL-1 $\beta$ in T. gondii infected THP-1 cells}

THP-1 cells were mock-infected or infected with RH strain of T. gondii at an MOI of $10 \mathrm{for} 4 \mathrm{hr}$ or $8 \mathrm{hr}$, and their morphology was then examined. To assess the capacity of differentiated THP-1 cells to produce IL-1 $\beta$ in response to T. gondii, THP-1 cells were infected with an MOI of 10 live T. gondii. Significant IL-1 $\beta$ synthesis was detected by western blotting in THP-1 cells after $4 \mathrm{hr}$ and $8 \mathrm{hr}$ of T. gondii infection (Fig. 1A). Using qRT-PCR, we detected the elevated levels of IL-1 $13 \mathrm{mRNA}$ after stimulation with T. gondii (Fig. 1B). T. gondii significantly enhanced IL-1 $\beta$ release in a time-dependent manner (Fig. 1C). These results indicated that $T$. gondii induces IL- $1 \beta$ processing and mature IL-1 $\beta$ secretion from THP-1 cells into the environment in a time-dependent manner.
Caspase- 1 and mRNA of NLRP1, NLRP3, NLRC4, and AIM2

Subsequent IL-1 $\beta$ processing is usually mediated by caspase- 1 , and the generation of mature IL- $1 \beta$ is achieved following cytoplasmic assembly and activation of inflammasomes [14-18]. T. gondii induced caspase-1 activation (cleaved caspase-1 p20) and pro-caspase-1 protein levels in THP-1 macrophages in an MOI-dependent manner (Fig. 2A). We then investigated components of the inflammasome pathway involved in the secretion of mature IL-1 1 . Therefore, we first examined expression levels of inflammasome sensors NLRP1, NLRP3, NLRC4, and AIM2 genes in T. gondii-infected THP-1 cells. qRTPCR analysis indicated that NLRP1, NLRP3, NLRC4, and AIM2 mRNA levels were significantly elevated after $4 \mathrm{hr}$ and $8 \mathrm{hr}$ of $T$. gondii infection (Fig. 2B). We also confirmed activation of NLRP3 and NLRC4 proteins using western blot (Fig. 2C).
A

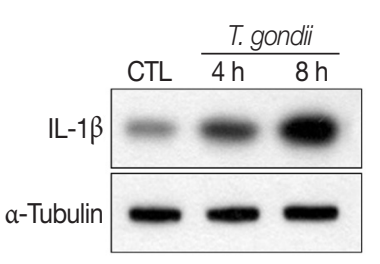

B

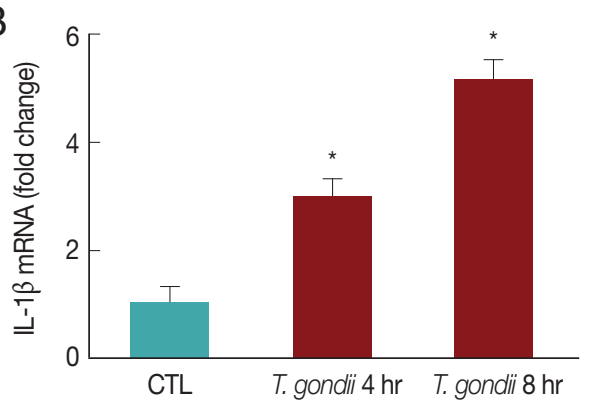

C

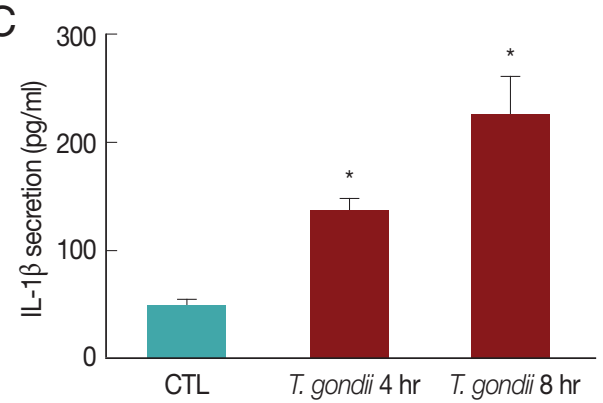

Fig. 1. T. gondii triggers the expression and secretion of mature $\mathrm{L}-1 \beta$. (A, B) THP-1 macrophages were mock-infected or infected with $\mathrm{RH}$ strain of $T$. gondii at an $\mathrm{MOI}$ of 10 for $4 \mathrm{hr}$ and $8 \mathrm{hr}$. IL-1 $1 \beta$ expression levels were quantified by western blotting (A) and qRT-PCR (B). (C) Culture supernatants were collected, and IL-1 $\beta$ levels were measured in the supernatants by ELISA. Results represent the means \pm $\mathrm{SD}$ from a representative of 3 independent experiments ( ${ }^{*} P<0.05$ compared with the control).

A

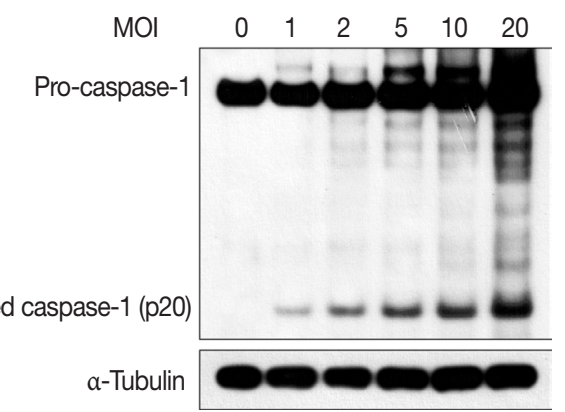

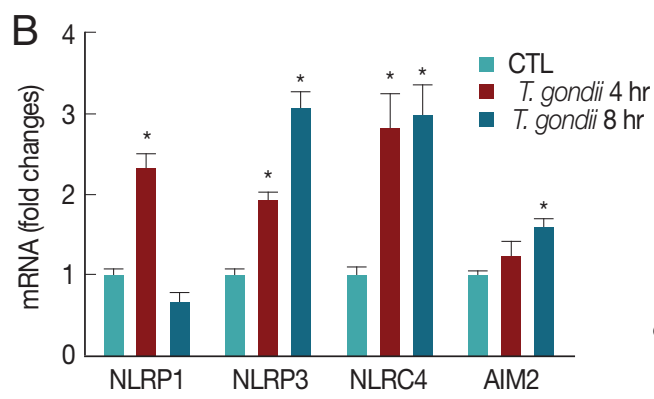

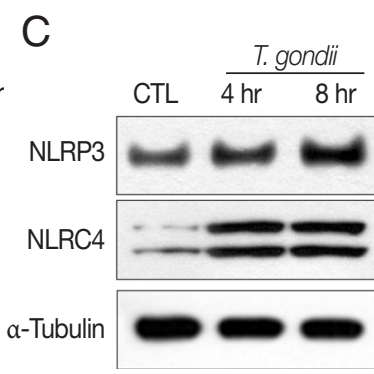

Fig. 2. T. gondii infection induces caspase-1 activation and elevates NLRP1, NLRP3, NLRC4, and AIM2. (A) THP-1 macrophages were mock-infected or infected with RH strain of $T$. gondii using different MOls for $8 \mathrm{hr}$. Cells were collected, and caspase- 1 expression levels were quantified by western blotting. The a-tubulin was used as a loading control. (B) THP-1 macrophages were mock-infected or infected with $\mathrm{RH}$ strain of $T$. gondii at an $\mathrm{MOI}$ of 10 . Cells were harvested at $4 \mathrm{hr}$ or $8 \mathrm{hr}$ post infection, RNA was extracted, and NLRP1, NLRP3, NLRC4, and AIM2 expressions were determined by qRT-PCR. HPRT1 was used as an internal control. (C) THP-1 macrophages were mock-infected or infected with $\mathrm{RH}$ strain of $T$. gondii at an MOI of 10 for $4 \mathrm{hr}$ or $8 \mathrm{hr}$. NLRP3 and NLRC4 protein levels in the cells were quantified by western blotting. The a-tubulin was used as a loading control. A representative of 3 independent replicates with similar results is shown ( ${ }^{*} P<0.05$, compared with the control). 
A

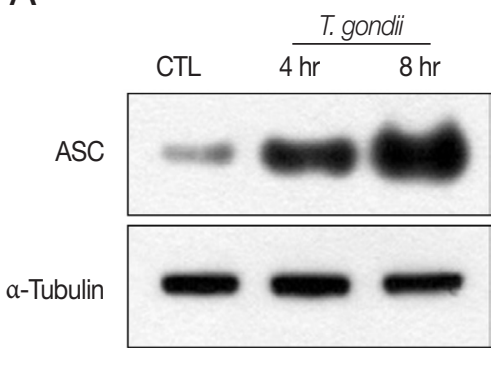

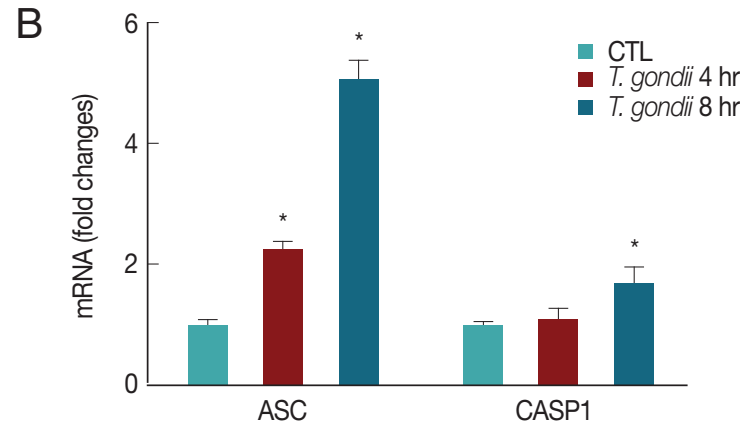

Fig. 3. T. gondii upregulates ASC mRNA and protein levels and caspase-1 mRNA levels. (A) THP-1 macrophages were mock-infected or infected with RH strain of T. gondii at an MOl of 10 for $4 \mathrm{hr}$ or $8 \mathrm{hr}$. ASC protein levels in the cells were quantified by western blotting. The a-tubulin was used as a loading control. (B) THP-1 macrophages were mock-infected or infected with RH strain of T. gondii at an $\mathrm{MOI}$ of 10. Cells were harvested at $4 \mathrm{hr}$ or $8 \mathrm{hr}$ post infection, RNA was extracted, and ASC and caspase-1 gene expression was determined by qRT-PCR. HPRT1 was used as an internal control. A representative of 3 independent replicates with similar results is shown $\left({ }^{*} P<0.05\right.$ compared with the control).

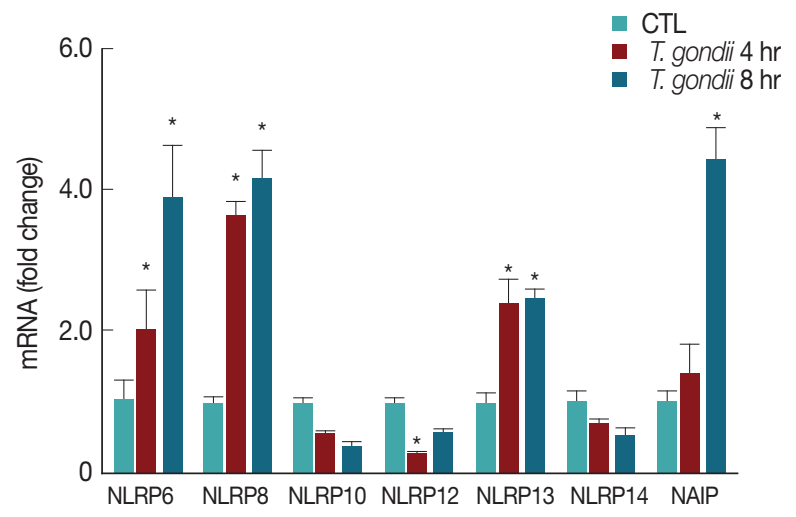

Fig. 4. T. gondii infection regulates a subset of NLRP genes and NAIP. THP-1 macrophages were mock-infected or infected with $\mathrm{RH}$ strain of $T$. gondii at an $\mathrm{MOI}$ of 10 . Cells were harvested at $4 \mathrm{hr}$ or $8 \mathrm{hr}$ post infection, RNA was extracted, and the expression of various genes was determined by qRT-PCR. HPRT1 was used as an internal control. A representative of 3 independent replicates with similar results is shown $\left({ }^{*} P<0.05\right.$, compared with the control).

\section{ASC protein and mRNA levels and caspase-1 mRNA levels}

We next determined whether T. gondii infection influences inflammasome adaptor protein ASC and caspase-1 expression levels. After $4 \mathrm{hr}$ and $8 \mathrm{hr}$ post infection, ASC protein levels were significantly increased in a time-dependent manner after infection with MOI 10 T. gondii (Fig. 3A). T. gondii also upregulated ASC and caspase-1 mRNA levels after $8 \mathrm{hr}$ (Fig. 3B).

\section{A subset of NLRP genes and NAIP}

A number of NLRP genes with unknown functions are expressed in THP-1 macrophages. T. gondii-infected THP-1 cells induced the elevation of NLRP6, NLRP8, and NLRP13 mRNA levels with a time-dependent manner. In contrast, NLRP10 and NLRP14 mRNA expressions were decreased in T. gondiiinfected THP-1 cells, but there were no significant differences between the mock-infected and T. gondii-infected groups. In addition, NLRP12 mRNA levels were significantly lower than those of the control after $4 \mathrm{hr}$ of $T$. gondii infection. Interestingly, T. gondii infection significantly elevated NAIP mRNA levels after 8 hr (Fig. 4).

\section{DISCUSSION}

Inflammasomes are activated by infection or stress and regulate the activity of caspase- 1 and maturation of IL- $1 \beta$ and IL$18[11,12,20]$. Canonical inflammasomes are composed of at least 3 main components; an inflammatory caspase, an adapter molecule such as ASC, and a sensor protein such as NLRP1, NLRP3, NLRP12, NAIP1, NAIP2, NAIP5, or AIM2 $[11,12,20]$. Activation of these molecules facilitate restriction of microbial replication and trigger an inflammatory form of cell death called pyroptosis, thus activating inflammatory processes $[12,20]$.

We examined the levels of IL-1 $\beta$, which is a pyrogenic cytokine that is produced during innate immune responses following pathogenic invasion. IL-1 $\beta$ is synthesized as an immature pro-IL-1 $\beta$, which requires activated caspase- 1 for its cleavage into mature IL-1 $\beta$, which is secreted from cells [20-22]. In previous studies, IL-1 $\beta$ production was induced in cells infected with T. gondii $[17,18,23,24]$. In this study, T. gondii-infected macrophages did not show any increase in secretion of IL-18 (data not shown), whereas elevated IL-1 $\beta$ secretion was detect- 
ed in T. gondii-infected THP-1 cells with a time-dependent manner. These results were similar to a previous report that, although T. gondii-infected macrophages showed efficient caspase-1/11-dependent IL-1 $\beta$ cleavage and secretion, they did not show upregulation, cleavage, or secretion of IL-18 [16]. Additionally, our experiments showed that pro-IL-1 $\beta$ mRNA expression in T. gondii-infected macrophages directly corresponded to the release of mature IL-1 $\beta$ protein.

To investigate the inflammasome pathways involved in the secretion of mature IL-1 $\beta$, we examined expression levels of sensor molecules modulated by T. gondii. Infection with T. gondii triggers NLRP1 and NLRP3 inflammasome formation, and a protective inflammasome-mediated response is induced to limit parasite load and dissemination [14-16,18]. In this study, we confirmed that $T$. gondii infection significantly elevated ligand recognition of inflammasome sensors, including NLRP1, NLRP3, adaptor molecule ASC, and caspase-1.

Additional receptors present in the plasma membrane or cytosol may be involved in inflammasome activation during $T$. gondii infection. We examined the expression of unknown sensor proteins, including NLRC4, NLRP6, NLRP8, NLRP10, NLRP12, NLRP13, NLRP14, AIM2, and NAIP. T. gondii infection significantly elevated NLRC4, NLRP6, NLRP8, NLRP13, AIM2, and NAIP mRNA levels in a time-dependent manner. To our knowledge, this is the first report to show that NLRC4, NLRP6, NLRP8, NLRP13, AIM2, and NAIP inflammasome sensors potentially contribute to the pathogenesis of $T$. gondii infection in THP-1 macrophages. Under specific conditions, NLRP6 is highly expressed in the gastrointestinal tract and forms inflammasomes with ASC and caspase-1 [25]. These results suggest that the inflammasome may play a key role in barrier function during homeostasis and intestinal inflammation induced by T. gondii infection. NLRP8 and NLRP13 are reproduction-related genes, but their actual role in inflammatory disease is not yet understood [26]. Interestingly, a recent study reported that NAIP/NLRC4 inflammasome complexes are activated in response to proteins from virulent bacteria that reach the cell cytosol [27]. Similar to these reports, we showed that $T$. gondii significantly elevated NAIP and NLRC4 mRNA levels in THP-1 macrophages. These results indicate that activation of the NAIP/NLRC4 inflammasome may occur in $T$. gondii-infected macrophages; however, the precise role of NAIP/NLRC4 requires further investigation.

ASC also known as target of methylation-induced silencing-1, is a putative component of the inflammasome complex
[11]. The inflammasome adaptor protein ASC mediates the recruitment and activation of caspase-1, thereby regulating caspase-1 mediated maturation of IL-1 $\beta$ [28]. These results are consistent with our findings that $T$. gondii infection significantly upregulates ASC protein and mRNA levels and induces parasite load-dependent caspase- 1 activation.

In summary, to elucidate the role of inflammasome components in the innate immune response to $T$. gondii infection in THP-1 macrophages, we examined inflammasome-related gene and protein expression and the mechanisms of inflammasome-regulated inflammatory cytokine secretion. In this study, T. gondii infection significantly increased the production of IL-1 $\beta$ in PMA-differentiated THP-1 macrophages. In addition, T. gondii infection significantly elevated the mRNA expressions of ligand recognition inflammasome sensors, including NLRP1, NLRP3, NLRC4, NLRP6, NLRP8, NLRP13, AIM2, NAID, ASC, and caspase-1. This study showed for the first time that T. gondii infection regulates NLRC4, NLRP6, NLRP8, NLRP13, AIM2, and NAIP gene expression. Investigation of the molecular mechanisms that activate these inflammasomes will require further investigation.

\section{ACKNOWLEDGMENTS}

This work was supported by the National Natural Science Foundation of China (81300368 and 81301449), the Special Funds of University Discipline and Specialty Construction in Guangdong Province, China (no. 2013LYM_0034), the Special Funds of Public Interest Research and Capacity Building of Guangdong Province, China (no. 2015A030302078), and the Foundation for Returned Overseas Scholars of Guangdong Medical College, China (no. B2012077).

\section{CONFLICT OF INTEREST}

The authors declare no conflict of interest related to this study.

\section{REFERENCES}

1. Flegr J, Prandota J, Sovičková M, Israili ZH. Toxoplasmosis-a global threat. Correlation of latent toxoplasmosis with specific disease burden in a set of 88 countries. PLoS One 2014; 9: e90203.

2. Montoya JG, Liesenfeld O. Toxoplasmosis. Lancet 2004; 363 : 1965-1976.

3. Yarovinsky F. Innate immunity to Toxoplasma gondii infection. 
Nat Rev Immunol 2014; 14: 109-121.

4. Kawai T, Akira S. Innate immune recognition of viral infection. Nat Immunol 2006; 7: 131-137.

5. Meylan E, Tschopp J, Karin M. Intracellular pattern recognition receptors in the host response. Nature 2006; 442: 39-44.

6. Olive C. Pattern recognition receptors: sentinels in innate immunity and targets of new vaccine adjuvants. Expert Rev Vaccines 2012; 11: 237-256.

7. Kumar H, Kawai T, Akira S. Pathogen recognition by the innate immune system. Int Rev Immunol 2011; 30: 16-34.

8. Yarovinsky F. Toll-like receptors and their role in host resistance to Toxoplasma gondii. Immunol Lett 2008; 119: 17-21.

9. Franchi L, Warner N, Viani K, Nuñez G. Function of Nod-like receptors in microbial recognition and host defense. Immunol Rev 2009; 227: 106-128.

10. Shaw MH, Reimer T, Kim YG, Nuñez G. NOD-like receptors (NLRs): bona fide intracellular microbial sensors. Curr Opin Immunol 2008; 20: 377-382.

11. Lamkanfi M, Dixit VM. Mechanisms and functions of inflammasomes. Cell 2014; 157: 1013-1022.

12. Davis BK, Wen H, Ting JP. The inflammasome NLRs in immunity, inflammation, and associated diseases. Ann Rev Immunol 2011; 29: 707-735.

13. Witola WH, Mui E, Hargrave A, Liu S, Hypolite M, Montpetit A, Cavailles P, Bisanz C, Cesbron-Delauw MF, Fournié GJ, McLeod R. NALP1 influences susceptibility to human congenital toxoplasmosis, proinflammatory cytokine response, and fate of Toxoplasma gondii-infected monocytic cells. Infect Immun 2011; 79: 756-766.

14. Wang S, Wang Z, Gu Y, Li Z, Li Z, Wei F, Liu Q. Toxoplasma gondii mitogen-activated protein kinases are associated with inflammasome activation in infected mice. Microbes Infect 2016; 18: 696700 .

15. Cirelli KM, Gorfu G, Hassan MA, Printz M, Crown D, Leppla SH, Grigg ME, Saeij JP, Moayeri M. Inflammasome sensor NLRP1 controls rat macrophage susceptibility to Toxoplasma gondii. PLoS Pathog 2014; 10: e1003927.

16. Gorfu G, Cirelli KM, Melo MB, Mayer-Barber K, Crown D, Koller BH, Masters S, Sher A, Leppla SH, Moayeri M, Saeij JP, Grigg ME. Dual role for inflammasome sensors NLRP1 and NLRP3 in murine resistance to Toxoplasma gondii. MBio 2014; 5: e01117-13.
17. Ewald SE, Chavarria-Smith J, Boothroyd JC. NLRP1 is an inflammasome sensor for Toxoplasma gondii. Infect Immun 2014; 82: 460-468.

18. Witola WH, Mui E, Hargrave A, Liu S, Hypolite M, Montpetit A, Cavailles P, Bisanz C, Cesbron-Delauw MF, Fournié GJ, McLeod R. NALP1 influences susceptibility to human congenital toxoplasmosis, proinflammatory cytokine response, and fate of Toxoplasma gondii-infected monocytic cells. Infect Immun 2011; 79: 756-766.

19. Satoh T, Otsuka A, Contassot E, French LE. The inflammasome and IL-1 $\beta$ : implications for the treatment of inflammatory diseases. Immunotherapy. 2015; 7: 243-254.

20. Dinarello CA. A clinical perspective of IL-1beta as the gatekeeper of inflammation. Eur J Immunol 2011; 41: 1203-1217.

21. van de Veerdonk FL, Netea MG, Dinarello CA, Joosten LA. Inflammasome activation and IL-1 $\beta$ and IL-18 processing during infection. Trends Immunol 2011; 32: 110-116.

22. Marshall ES, Elshekiha HM, Hakimi MA, Flynn RJ. Toxoplasma gondii peroxiredoxin promotes altered macrophage function, caspase-1-dependent IL-1 $\beta$ secretion enhances parasite replication. Vet Res 2011; 42: 80.

23. Nagineni CN, Detrick B, Hooks JJ. 2000. Toxoplasma gondii infection induces gene expression and secretion of interleukin 1 (IL1), IL-6, granulocyte-macrophage colony-stimulating factor, and intercellular adhesion molecule 1 by human retinal pigment epithelial cells. Infect Immun 2000; 68: 407-410.

24. Quan JH, Cha GH, Zhou W, Chu JQ, Nishikawa Y, Lee YH. Involvement of PI 3 kinase/Akt-dependent Bad phosphorylation in Toxoplasma gondii-mediated inhibition of host cell apoptosis. Exp Parasitol 2013; 133: 462-471.

25. Sellin ME, Maslowski KM, Maloy KJ, Hardt WD. Inflammasomes of the intestinal epithelium. Trends Immunol 2015; 36: 442-450.

26. Kim YK, Shin JS, Nahm MH. NOD-like receptors in infection, immunity, and diseases. Yonsei Med J 2016; 57: 5-14.

27. Lage SL, Longo C, Branco LM, da Costa TB, Buzzo Cde L, Bortoluci KR. Emerging concepts about NAIP/NLRC4 inflammasomes. Front Immunol 2014; 5: 309.

28. Gov L, Karimzadeh A, Ueno N, Lodoen MB. Human innate immunity to Toxoplasma gondii is mediated by host caspase- 1 and ASC and parasite GRA15. MBio 2013; 4: e00255-13. 
